\title{
Planning the Integrated Mold Design Course with CDIO Concept
}

\author{
Cheng-Tang Tseng, Kuo-Cheng Tai, and Ching-Yi Lee
}

\begin{abstract}
This study aims to devise a set of mold design course modules that are based on conceive, design, implement, and operate (CDIO) teaching model. The goal is to cultivate future talents in the mold industry and to solve the global problem of university graduates being unable to meet practical needs. To coordinate with the development of industrial systematic engineering, we devise six disciplines based on the mold industry from the product life cycle and adopted the "precise mold system design practice" as the Capstone course to carry out the integrated course design of CDIO. In Learning Outcomes, to ensure that the output meets the needs of the industry, the subjects were designed based on the Mold Design Competency Projects. In Benchmarking of the Existing Curriculum, we use the "competence project and course unit correlation matrix" to let teachers know what to teach, what proportion and order? Finally, we used the course organizing principles, with skills and projects interwoven to develop an integrated curriculum modular structure. That links the basic disciplines and professional subjects with each other and support each other, and established a team cooperation model to enable students to solve complex engineering problems and achieve the goal of CDIO engineering education reform. The research results have been applied to the precise system design course of Feng Chia University. After four years of experimental teaching and curriculum revision, the CDIO integrated teaching model has reached a more mature level.
\end{abstract}

Index Terms-CDIO, competency, integrated course, mold design.

\section{INTRODUCTION}

In recent years, due to changes in the industrial structure and market demand, the mold industry in Taiwan has gradually transformed from the traditional OEM to a high-precision mold factory that is integrated with the production system. In response to the new development trend in the International Industry 4.0, Taiwan has provided the best opportunity for the quick development of the mold industry in the integration of smart factories and systems engineering with advanced capital technology, excellent machines, and automation equipment. At the same time, the mold industry in Taiwan also suffers from the threat of small-scale business, international trade barriers, and shortage of well-trained labor. There are two serious problems in the industry and the academic field in the field of precision mold technology. Owing to advancements in the precision mold industry, Taiwan's young mold technicians have lost the opportunity for technical development, which has caused a gap in the industry's technology heritage. In the

Manuscript received June 25, 2018; revised January 24, 2019.

The authors are with Feng Chia University, Taiwan (e-mail: luke.mold@gmail.com,kctai@fcu.edu.tw, cyilee@fcu.edu.tw). academic field, Taiwan's long-term education leans toward academics and ignores the practical knowledge. The education reform doesn't pay off and teachers are inadequate in engineering practices, resulting in serious gaps between theoretical and practical knowledge among students. To overcome these problems, the government has combined the strengths of various sectors of industry, government, academia, and research to promote multiple training programs, the formulation of competency benchmarks, and the licensing of technicians, among others, in an effort to eliminate the technical gaps in the industry. This study believes that the fundamental solution to overcome this problem is to eliminate the gap between learning and practicing and to align the college engineering education with vocational training. Therefore, this study attempts to use the concept of Conceive, design, implementation, and operate (CDIO) higher engineering education to devise a set of mold design teaching units. The purpose is to solve the problems of learning gaps and to prepare future mold design talents for the industry.

It is expected CDIO model will not only benefit the scholars but will also bridge the gap between the theoretical and practical knowledge. On one hand, students learn about the professional knowledge of engineering foundation theory. On the other hand, by product life cycle such as conceiving, designing, implementing, and operating, students will have practical hands-on skills, practical theoretical knowledge, and reflective learning experiences. The process will also inspire students' enthusiasm and motivation for active learning.

In general, planning an innovative pedagogical ways to make double duty of teaching time so that students can learn the skills of basic disciplines and operate CDIO technology at the same time, is the challenge of the CDIO Engineering Education Integrated Curriculum [1].

The course unit design method first considers the engineering scope of Mold industry in its product life cycle as the blueprint to carry out the curriculum development and syllabus planning. Second, the competency projects and indicators were used to measure the learning effect of the course. Third, the current course was edited by the competency projects and curriculum units related matrix. Finally, an integrated curriculum modular structure was developed to complete the mold design course unit with the CDIO concept.

\section{LITERATURE REVIEW}

\section{A. The Concept of CDIO}


CDIO, jointly promoted by the Massachusetts Institute of Technology, Chalmers University of Technology in Sweden, Linkoping University, and the Royal Institute of Technology in 2000, is a cultivation model for educating engineering talents. It is one of the most successful and influential example of engineering education reform in the world. The CDIO includes three core values: 1 vision, 1 outline, and 12 criteria. Its vision is "Adoption of the principle that product, process, and system lifecycle development and deployment-Conceiving, Designing, Implementing and Operating - are the context for engineering education [2]. The purpose of higher engineering education is to cultivate the competency of future engineers across a variety of disciplines. The importance of these disciplines education is related to the employment and career development of graduates. [3] The CDIO engineering education model aims to achieve the following three reform goals through the reform of the education system:

1) Enable students to make more active use of the basic engineering theory of the course.

2) Construct new product development procedures and master the operation of system engineering.

3) Understand the importance of engineering technology development and research on society and their future impact.

Among these, the first goal is to emphasize that teachers should focus on inspiring students' understanding and the application of basic concepts when they are teaching fundamental theory of engineering, rather than expecting students to passively accept knowledge, as suggested by Marton and Saljo. Heuristic "deep teaching method" should replace the "top-level teaching method" which is literally spoon fed [4]. The second goal is to emphasize the development of students' abilities, apply basic engineering knowledge to specific topics, master the process from new products development to systems engineering operations, cultivate the ability to actively study and solve problems, master professional technics integrated by practice and basic engineering knowledge, and develop personality traits and interpersonal skills through teamwork, preparing for future professional careers with knowledge, technology, and attitude. The third goal is to realize the contribution of current engineering education to the society and its impact on our life. Students can contribute to the industry, academia, society, and country by establishing engineering ethics, values, and sense of responsibility.

CDIO is different from the traditional teaching model because it has several characteristics. They are a) learning from practice: thematic-oriented teaching through practical engineering operation, b) design concept based on demand: using the needs of the user as the core of creativity and thinking to inspire a real-world engineering design thinking, c) product selling and market planning: taking into account product $\mathrm{R} \& \mathrm{D}$, production, marketing, and service design, it is a complete operating strategy for the product life cycle, d) cross-field teamwork: combine professional members from different fields to jointly conduct engineering $R \& D$ to foster teamwork, communication and leadership, and cultivate problem solving capabilities [5].

\section{B. Curriculum Development Based on the Product Life Cycle Management (PLM)}

"Mold" can be simply referred to as producing equipment for certain products. Most of the physical goods rely on mass production of molds. In general, PLM can be divided into four phases, which are conceive, develop, realize, and use, as shown in Fig. 1 [6]. The mold industry is now between the "develop" and "realize" phases. It is the beginning of putting ideas into practice and the most important process of product commercialization. The curriculum design in this study is based on the precise system design course of the first semester of sophomore year at Feng Chia University. The "PRECISION MOLD SYSTEM DESIGN" is used as a capstone course, and the combination of "AESTHETIC DESIGN," "GREEN PRODUCT DESIGN," "PRECISION MOLD," "CAD/3D DRAWINGS," "2D DRAWINGS," and "MOLD PRACTICE" are six disciplinary courses. The purpose of this integrated curriculum is to guide students to use the concepts of creativity, basic graphics, and precision system that are learned from freshman year. In this basis, to complete requirements from the market needs, creative research and development, product design, mold evaluation, mold design, and engineering drawings, among others, and perform system engineering tasks, such as product development (RD) and mold design (MD), in the form of team work, project leader(PL), and project management(PM).

In Fig. 1, the integrated curriculum starts with the concept of conceive in the product life cycle, through development to the realization, the relative technology core includes PDM and CAx. The methods are concurrent and DFMA, required tools are CAID, CAD, CAE, and ASP, and the correspondences between various disciplines and product life cycle technologies are shown in Table I.

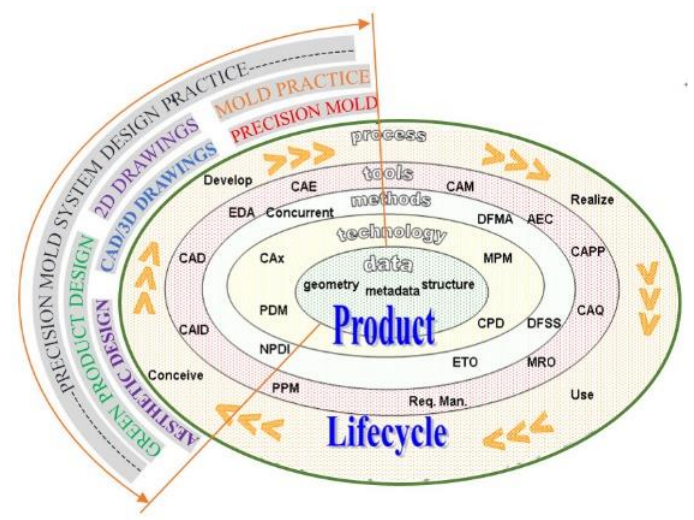

Fig. 1. The scope of the integrated curriculum in the PLM.

TABLE I: COURSES AND PLM TECHNICAL CORRESPONDENCE TABLE

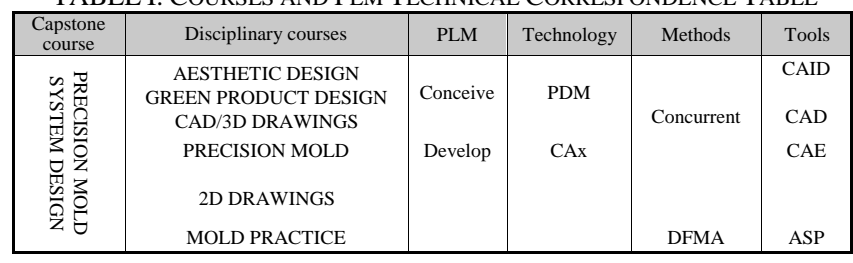

The "precise mold system design practice" of the capstone course will coordinate all the disciplinary courses, cultivate students' professional capabilities in practice from product development to $\mathrm{MD}$, and execute product $\mathrm{R} \& \mathrm{D}$ and $\mathrm{MD}$ 
projects in a team-based manner. The results will be published at the end of the semester. Students will use the knowledge and technology learned in the course, to complete the task from product development to mold design with creative thinking and write reports. Therefore, this course will focus on the development of the abilities of C and D, and the ability of I will be gradually developed in the topic of summary to link to the junior high-precision mold manufacturing course, Table II is the correspondence table of the four major axes in the CDIO curriculum for each subject of the integrated curriculum.

TABLE II: COURSES AND THE FOUR MAIN SPINDLES CORRESPONDENCE TABLE

\begin{tabular}{|c|c|c|c|c|c|c|c|c|c|c|c|c|c|c|c|c|c|c|}
\hline \multicolumn{19}{|c|}{ TABLE } \\
\hline Courses & & & 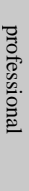 & & & 5 & & $\begin{array}{l}\stackrel{N}{0} \\
\text { D } \\
\vec{U} \\
\stackrel{0}{0}\end{array}$ & & & 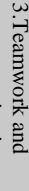 & & & & & 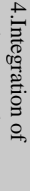 & & \\
\hline & ڤ̊ & 1 & 2 & 3 & 1 & 2 & 3 & 4 & 5 & 1 & 2 & 3 & 1 & 2 & 3 & 4 & 5 & \\
\hline AESTHETIC DESIGN & 1 & & $\mathrm{v}$ & & & $\mathrm{v}$ & & & & $\mathrm{v}$ & & & & $\mathrm{v}$ & $\mathrm{v}$ & & & \\
\hline GREEN PRODUCT DESIGN & 3 & $\mathrm{v}$ & $\mathrm{v}$ & $\mathrm{v}$ & $\mathrm{v}$ & $\mathrm{v}$ & $\mathrm{v}$ & $\mathrm{v}$ & $\mathrm{v}$ & $\mathrm{v}$ & $\mathrm{v}$ & & $\mathrm{v}$ & & $\mathrm{v}$ & $\mathrm{v}$ & $\mathrm{v}$ & \\
\hline PRECISION MOLD & 3 & $\mathrm{v}$ & $\mathrm{v}$ & $\mathrm{v}$ & $\mathrm{v}$ & $\mathrm{v}$ & & $\mathrm{v}$ & $\mathrm{v}$ & $\mathrm{v}$ & & & $\mathrm{v}$ & & & & & \\
\hline CAD/3D DRAWINGS & 3 & & $\mathrm{v}$ & $\mathrm{v}$ & & $\mathrm{v}$ & $\mathrm{v}$ & & $\mathrm{v}$ & $\mathrm{v}$ & & & & & & $\mathrm{v}$ & & \\
\hline MOLD PRACTICE & 1 & & $\mathrm{v}$ & $\mathrm{v}$ & $\mathrm{v}$ & $\mathrm{v}$ & & $\mathrm{v}$ & $\mathrm{v}$ & $\mathrm{v}$ & $\mathrm{v}$ & & & & & 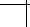 & $\mathrm{v}$ & $\mathrm{v}$ \\
\hline 2D DRAWINGS & 1 & & & $\mathrm{v}$ & $\mathrm{v}$ & & & $\mathrm{v}$ & $\mathrm{v}$ & & & & & & $\mathrm{v}$ & $\mathrm{v}$ & $\mathrm{v}$ & $\mathrm{v}$ \\
\hline $\begin{array}{l}\text { PRECISION MOLD SYSTEM } \\
\text { DESIGN }\end{array}$ & 3 & $\mathrm{v}$ & $\mathrm{v}$ & $\mathrm{v}$ & $\mathrm{v}$ & $\mathrm{v}$ & $\mathrm{v}$ & $\mathrm{v}$ & $\mathrm{v}$ & $\mathrm{v}$ & $\mathrm{v}$ & & $\mathrm{v}$ & $\mathrm{v}$ & $\mathrm{v}$ & $\mathrm{v}$ & $\mathrm{v}$ & \\
\hline
\end{tabular}

\section{Definition of Integrated Course}

The integrated course can be briefly explained as the integration of discipline basic theory and engineering application technology, and the integration of system construction, operation, and individual and team cooperation abilities. The design process and model of the integrated course are shown in Fig. 2, in which the basis of the curriculum is derived from competency projects, indicators and a coordination session with the teacher. The professional competency projects and competency indicators are based on the results of stakeholder surveys. The stakeholders include industry representatives, school educational development units, and teachers and students, among others, which are developed through interviews, questionnaires, and literature discussions. Combined with the school's educational philosophy and the core competencies of the department, we developed the CDIO syllabus and set the learning effects of the course. The teacher's course meeting invites the teachers to participate in the CDIO program and completes the competency projects and curriculum units related matrix questionnaire in an attempt to re-adjust, arrange, combine, and organically connect the existing curriculum in the school.

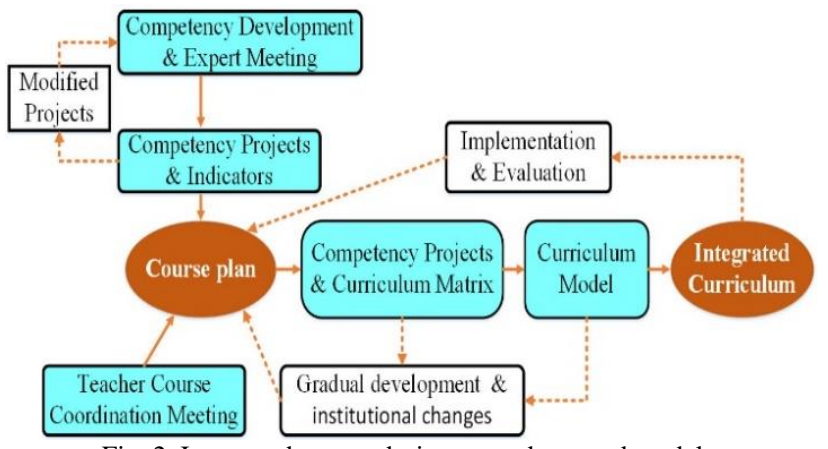

Fig. 2. Integrated course design procedures and models.
The next step is to develop a modular structure of integrated courses, which must be equipped with the following features: [2]

- Define learning outcomes explicitly with functional items and indicators.

- An integrated curriculum, skills and project intertwined curriculum organization principles.

- An innovative curriculum structure focuses on engineering and skills as part of the regular curriculum.

\section{RESEARCH AND DESIGN}

In the current era of rapid industry changes and companies facing global competition, aligning talent development with industrial development and business needs and plan appropriate education and training courses is an important task for the government. In advanced countries, human resources training can meet the needs of the industry. It not only attaches importance to the amount of investment in vocational training but also serves as a linking mechanism for smoothing the supply and demand at both ends of human resources through the establishment of industrial competency projects and indicators. The competency requirements for specific positions are used to plan the corresponding training and cultivating courses [7]. According to the CDIO curses model, the CDIO syllabus was designated as a formal learning output. However, the CDIO syllabus is a list of knowledge, skills and attitudes required for graduate engineers, and meets a variety of engineering professional benchmarks and is reviewed by experts in many fields. [2] For this reason, this study uses the developed competency projects and indicators as learning effects to replace CDIO syllabus. In doing so, it can also respond to the Integrated Competency and Application Platform promoted by the current Taiwan official: Workforce Development Agency. To enable students in school to use the engineering technology standards in employment as an indicator of learning, so that the university's engineering education is more in line with Taiwan's industrial demand.

\section{A. Establish Mold Design Competency Projects and Indicators}

The establishment of mold design competency projects and indicators can be divided into the following two steps, as shown in Fig. 3. The first step is to formulate a manpower policy based on the vision and goals of the Industry 4.0 smart mold factory, and to revise the "job description" from the interaction between the job analysis of the mold design process and the division of labor in the design department. This will redefine competency projects.

The second step is based on the competency project. By literature review, expert interviews, expert meetings, and other methods, we can build a mold design competency benchmarks and then establish the competency indicators based on each job requirement and the technical ability classification (basic, intermediate, and advanced).

The mold design competency project established in this study can be divided into three categories, nine parts, and 36 items, as shown in Table IV. 


\section{B. Establish a Competency Projects and Curriculum Units Related Matrix}

To understand the expected learning effects of the curriculum units in various disciplines and their relevance to competency projects, this study conducted several teachers course coordination meetings. The list of interviewing teachers is shown in Table III below. The purpose of these meetings was to invite teachers to participate in the design of CDIO integrated curriculum, complete the questionnaires related to the competency projects, and the course units in the existing curriculum, as shown in Table IV.

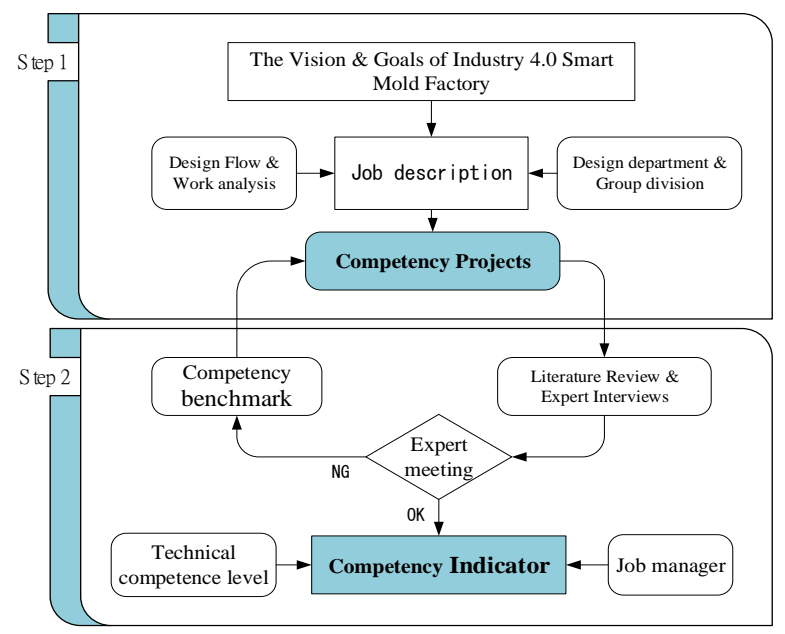

Fig. 3. Steps to establish mold design competency projects and indicators.

The principle of the establishment of this matrix is to use 36 competency items as vertical columns and the course units of the subjects as horizontal bars. Through the intersection of arrays, we can know the relation between each course unit and competency project. The questionnaire is filled in by the teachers according to the course contents by teaching order. The teachers must enter the relevance between each course unit and 36 competency items in the matrix box. There are CDIO attributes and corresponding course output supporting materials for each course unit. Two important data can be obtained from statistical results; the first data are used to understand the relevance between curriculum unit of each discipline and the corresponding 36 competency projects. The second data is to understand the ratio of the course units of each subject to the CDIO attributes.

\begin{tabular}{|c|c|c|}
\hline Name & Curriculum & Credit \\
\hline Teacher Liu & CAD/3D DRAWINGS & 3 \\
\hline Teacher Chen & PRECISION MOLD & 3 \\
\hline Teacher Yang & GREEN PRODUCT DESIGN & 3 \\
\hline Teacher Tseng & $\begin{array}{l}\text { PRECISION MOLD SYSTEM } \\
\text { DESIGN }\end{array}$ & 3 \\
\hline Teacher Lu & AESTHETIC DESIGN & 1 \\
\hline Teacher Lee & MOLD PRACTICE & 3 \\
\hline Teacher Lee & 2D DRAWINGS & 1 \\
\hline
\end{tabular}

\section{Integrated Curriculum Modularization Structure}

The integrated curriculum with the core of engineering consists of courses in Introductions, Basic Sciences,
Professional Subjects and Capstone Projects. Based on the curriculum organization principles and combination types above, the integrated curriculum modularization structure is shown in Fig. 4. The integrated curriculum can be divided into two parts:

TABLE IV: COMPETENCY PROJECTS AND CURRICULUM UNITS RELATED MATRIX QUESTIONNAIRE

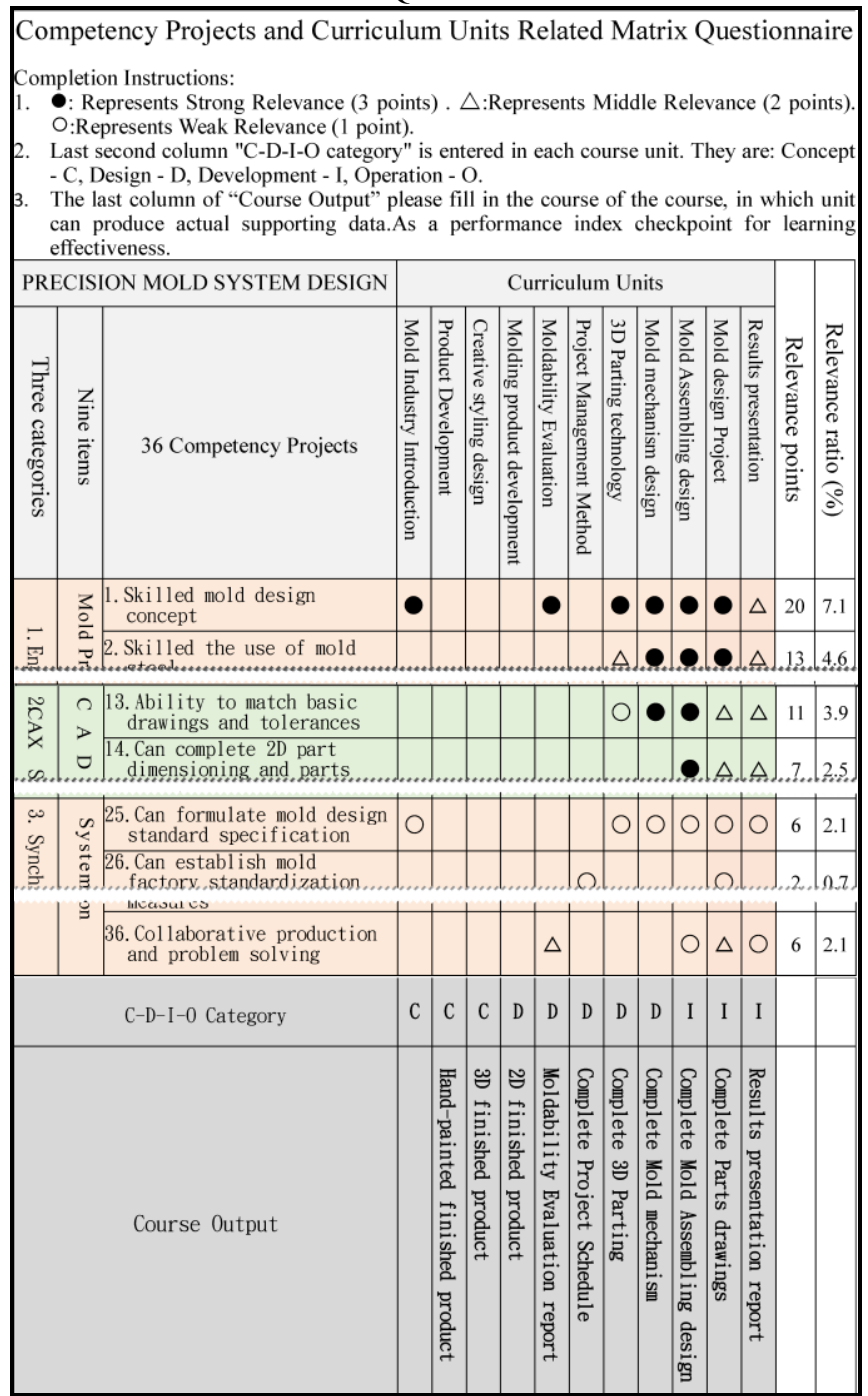

The first part is the Introductory Courses composed of industry introduction. Through simple application of engineering practices, students will be interested in the knowledge and topics of the field of engineering; moreover, they will proactively takes participation in the course. In addition, the introductory courses also provide a good opportunity for them to develop personal and interpersonal skills, also, the ability to build products, processes, and systems. According to the benefits mentioned previous, the course can be served as a basic framework for the succeeding curriculum.

The second part is the Capstone Projects which linking various Science Courses and Professional Courses. Such integrated courses has the following features:

1) Science Course and Professional Course are associated with each other and support each other.

2) The units of Science Course and Professional Course correspond to the learning effects of Capstone Course.

3) The Capstone Projects can be managed as a mean to 
decompose from the perspective of project management. In order to achieve the goal of horizontal tandem, it is necessary to combine the knowledge and skills according to the attributes of the tasks.

4) In the process of teamwork, the Capstone Projects can solve engineering problems and cast around for answers in various disciplines to achieve the cross-linking effect of CDIO capabilities.

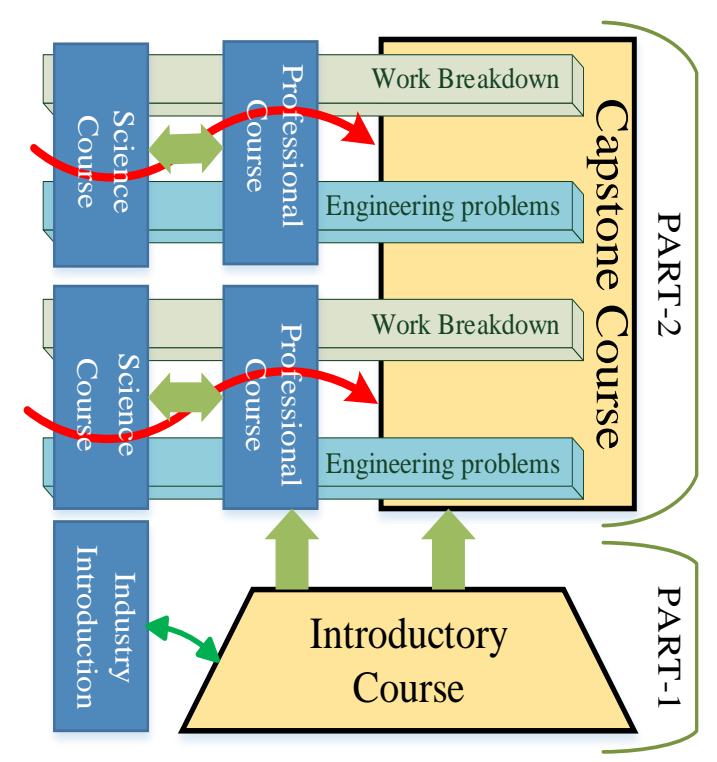

Fig. 4. Integrated curriculum modularization structure diagram.

\section{RESULTS}

This study conducted a questionnaire survey of six teachers of this course. The statistical results of the questionnaire collection are as follows. The first data is presented in Fig. 5, which is the curve graph of the proportion of the competency items of the relevance of the course unit and training priority. The solid line curve shows the proportion of all the six disciplines of the experimental course that are distributed in 36 competency items and is the result of the survey. The dotted line represents the training priority of the 36 competency items, which is the result of industry expert interview. Sophomore students are the subject for this experimental course and are considered as beginners. The training course should focus on the basic technical training and core technical training of the technical ability level. Therefore, the two curves should show the same trend to correspond with the course design principles for beginners' training. In general, except for the variation points noted in P1-P4 in the figure, most of the solid curve conforms to the regular waveform change of the dotted curve. To explore the causes

P1: Competency item number 5 (learn about plastic material properties) is lower than item number 6 (understanding product design points), showing that the proportion of practical teaching of product design in the course is higher than that of the basic science of material properties, which seems to conform with the teaching principle of CDIO.

P2: Competency item number 9 (understand the principle of injection molding) is low. This suggests that the teacher can increase the proportion of the relevant course units.

P3: Competency item number 29 (ability to have word processing and briefings) is low. In this experimental course, there are no related curriculum units for the training of word processing. Although the technology should be classified as common ability and are not in the scope of training of professional functions, the practical training of ad-hoc group meetings and work briefings can strengthen students' ability of word processing and data briefing.

P4: Competency item number 33 (team cooperation and communication coordination) is low. Like P3, there is no direct training course for this ability in this experimental course, but the summative topic of the product development task force will be the best training to improve students' ability, such expectations can be verified from the subsequent evaluation of teaching effectiveness.

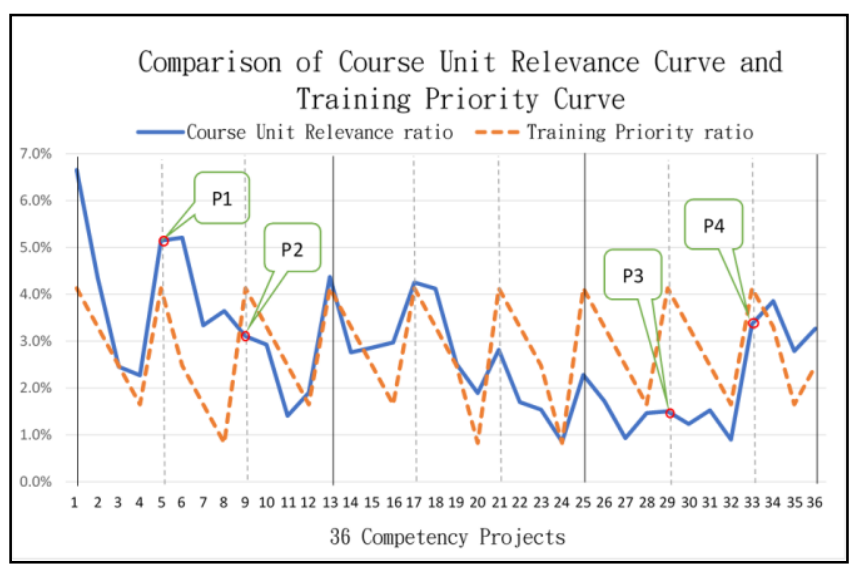

Fig. 5. Comparison of course unit relevance curve and training priority curve.

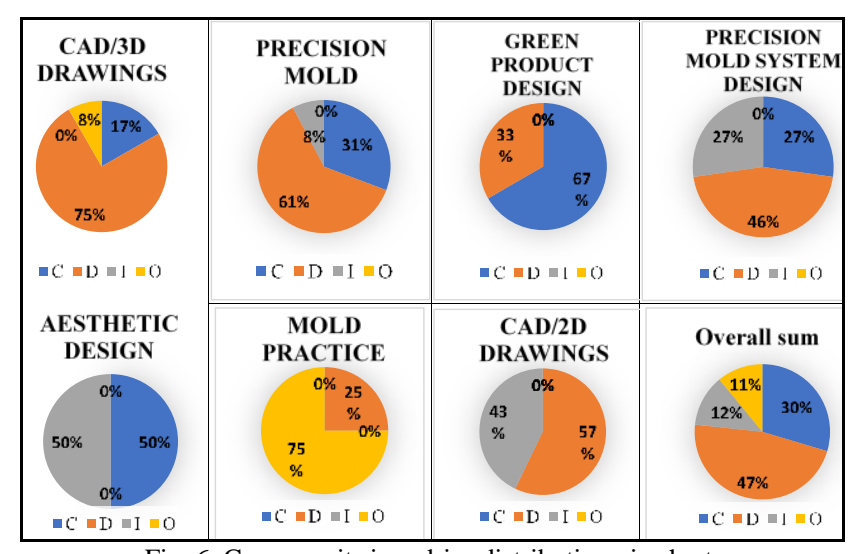

Fig. 6. Course units in c-d-i-o distribution pie chart.

The second data are presented in Fig. 6. We can clearly see the distributed pie charts for each discipline in the CDIO curriculum unit. This can provide course designers with an understanding of the course attributes. It can also be used in the teachers course coordination meeting, where it can provide reference for the curriculum unit adjustment and teaching sequence for teachers in various disciplines. Fig. 5 shows that the overall distribution of $\mathrm{CDIO}$ is $\mathrm{C}=30 \%, \mathrm{D}=$ $47 \%, \mathrm{I}=12 \%$, and $\mathrm{O}=11 \%$. We can see that the attributes are biased toward $\mathrm{C}$ and $\mathrm{D}$, and their sum total is as high as $77 \%$. In terms of the subject of the course set in this study, mold synchronization, it seems to be in line with the curriculum attributes that are biased toward conception and design. As for I and $\mathrm{O}$, it will be implemented in a coherent 
course in junior year.

\section{CONCLUSION}

This CDIO integrated curriculum model has been implemented in experimental teaching at Feng Chia University for the last 4 years. Based on the teaching experience of the scope of this study, we conducted the following discussion:

This study takes the mold industry in the scope of the PLM. According to the engineering sequence and the corresponding technical ability development curriculum combination method, it can better implement the CDIO education model, consider engineering as a core of the education concept, and can provide students with substantial help in understanding the engineering system and its operation.

This study uses competency projects and indicators as the learning effect of CDIO teaching to replace the CDIO syllabus. Such practice does not violate the teaching philosophy of CDIO, and it can better integrate the competency development results of various sectors in Taiwan, such as industry, government, education, and research. It can also design teaching model for higher education that is more in line with the industry demand.

Using the method of the competency project and the course unit matrix, the course unit can focus on each competency project, eliminating the gaps between learning and practice. By comparing the course unit connection curve with the function priority curve, the proportion of courses and the teaching order can be adjusted to avoid inadequate teaching and repetitive teaching in various disciplines.

Using the method of competency project and the course unit matrix, we can understand the distribution of all the courses in the CDIO attributes and can also verify the effectiveness of the learning according to the curriculum output certification materials filled in by teachers.

\section{REFERENCES}

[1] J. Bankel, K. F. Berggren, M. Engström, I. Wiklund, E. F. Crawley, D. Soderholm, K. E. Gaidi, and S. Östlund, "Benchmarking engineering curricula with the CDIO syllabus," Int. J. Engng Ed., vol. 21, no. 1, pp. $121-133,2005$
[2] E. Crawley, J. Malmqvist, S. Ostlund, and D. Brodeur, Rethinking Engineering Education: The CDIO Approach, 2nd ed. Springer Singapore: Springer, 2014, ch. 1, pp. 2-3.

[3] A. Lunev, I. Petrova, and V. Zaripova, "Competency-based models of learning for engineers: a comparison," European Journal of Engineering Education, vol. 38, no. 5, pp. 543-555, June 2013.

[4] F. Marton and R. Säljö, "Approaches to learning," The Experience of Learning, Edinburgh: Scottish Academic Press, 1984.

[5] C. Y. Lee, J. J. Wu, and B. T. Wang, "Conceive-design-implement-operate CDIO concept inspired engineering education in Taiwan," Taiwan Education Review Monthly, vol. 5, no. 2, pp. 101-104, 2016.

[6] STPI Technology Industry Information Office. (2007). Product Lifecycle Management (PLM) and Its Content. [Online]. Available: http://cdnet.stpi.narl.org.tw/techroom/analysis/pat_A104.htm

[7] Workforce Development Agency. (2018). Integrated Competency and Application Platform. [Online]. Available: https://icap.wda.gov.tw/Knowledge/knowledge_standard.aspx.

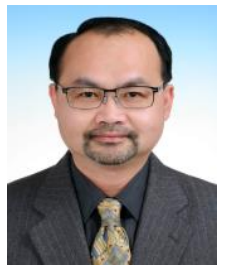

Cheng-Tang Tseng was born in Taichung city, Taiwan (R. O. C.) on Jan. 27, 1967. He is with Ph.D. Program of Mechanical and Aeronautical Engineering, Feng Chia University, Taiwan.

His major field of study includes mold system design, engineering education.

He was a professional mold designer with over 20 years of experience and owns a mold design company. Since 2012 to study Ph.D. Program of Mechanical and Aeronautical Engineering, Feng Chia University. And he is also an adjunct assistant professor who teaches precision mold system design as a professional. In recent years Mr. Tseng has been studying industry-academy cooperation cloud platform \& teaching cloud platform.

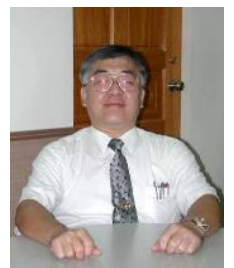

Kuo-Cheng Tai was born in Taichung city, Taiwan ( $\mathrm{R}$. O. C.). He is with bachelor program in precision system Design, Feng Chia University, Taiwan 40724, R.O.C. His major field of study includes computer-aided design and manufacturing. He is the chairman of bachelor program in precision system design, Feng Chia University. In recent years he has assisted many companies in introducing the concept of Industry 4.0 and brought many experiences gained in the industry into teaching to guide students.

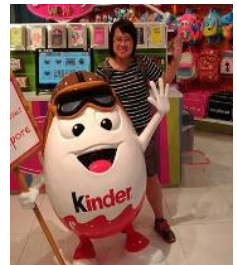

Ching-Yi Lee was born in Taichung city, Taiwan $(\mathrm{R}$ O. C.). She is with D.School, Feng Chia University, Taiwan 40724, R.O.C. Her major field of study indlucdes engineering education. She is currently a post-doctoral fellow in the $\mathrm{d}$. School at Feng Chia University. She is also an ADJUNCT ASSISTANT PROFESSOR who teaches creative thinking and design thinking. Dr. Lee current research focuses on engineering education, structural equation modelling, imagination, vocational training and higher education. 